CIVICS EDUCATION AND SOCIAL SCIENSE JOURNAL(CESSJ)

Volume 3 Nomor 1 Edisi Bulan Juni 2021

\title{
PENINGKATAN KEMAMPUAN GURU MENERAPKAN MODEL PEMBELAJARAN KOOPERATIF LEARNING MELALUI SUPERVISI AKADEMIK DI SDN O4 PAYARAMAN
}

\author{
ABDUL GANI \\ Kepala SDN 04 Payaraman
}

\begin{abstract}
ABSTRAK
Penelitian Tindakan Sekolah (PTS) ini bertujuan untuk meningkatkan kinerja guru dalam menerapkan model pembelajaran kooperatif sebagai alternatif pemecahan masalah rendahnya nilai siswa di SDN 04 Payaraman Kecamatan Payaraman Kabupaten Ogan Ilir. PTS dilakukan melalui suvervisi terhadap guruguru yang ada di SDN 04 Payaraman. Subjek dri penelitian ini adalah seluruh guru-guru SDN 04 Payaraman. Supervisi disini diartikan sebagai supervisi yang lebih menitik beratkan kepada pengamatan supervisi pada asfek administratif dan berfungsi sebagai pendukung kelancaran pelaksanaan proses belajar mengajar di sekolah. Adapun yang menjadi acuan berkembangnya tujuan penelitian yang dilakukan penulis adalah: a) Mengetahui kompetensi profesionalisasi, b)Merefleksikan profesinya dalam kehidupan sehari-hari, c)Secara administratif guru mampu memanfaatkan dan menggunakannya dalam tugas keseharian di lapangan. Kegiatan penelitian dilakukan melalui suatu pendekatan observasi dengan menggunakan instrumen pengamatan, survey serta prosedur penelitian yang langkah-langkahnya: 1)Perencanaan, 2)Pelaksanaan tindakan, 3)Observasi, 4)Refleksi. Dari kajian di atas, dihasilkan bahwa kompetensi profesional guru dalam pengerjaan administrasi pembelajaran yang dilakukan guru disinyalir belum maksimal. Dan setelah dilakukan penelitian tindakan sekolah melalui tahapan siklus terdapat kontribusi positif yang cukup signifikant hal ini dibuktikan dengan prosentasi hasil supervisi akademik skor rata - rata sbb:1), Siklus satu menunjukan rata-rata 68,04\%, 2) Siklus dua memperlihatkan peningkatan dengan angka rata-rata 94,00\%. Artinya perubahannya memiliki konstribusi yang cukup signifikan, karenanya penelitian ini dapat memperoleh manfaat yang cukup baik pula.
\end{abstract}

Kata kunci : Kinerja Guru, Supervisi Akademik

JORNAL PROGDI PPKn, FKIP UNIVET BANTARA SUKOHARJO BEKERJA SAMA DENGAN ASSOSIASI PROFESI PENDIDIKAN PANCASILA DAN KEWARGANEGARAAN (AP3KNI) JAWA TENGAH 
CIVICS EDUCATION AND SOCIAL SCIENSE JOURNAL(CESSJ)

Volume 3 Nomor 1 Edisi Bulan Juni 2021

\section{PENDAHULUAN}

Menurut UU No.20 tahun 2003 tentang Sistem Pendidikan Nasional bahwa pendidikan adalah usaha sadar dan terencana untuk mewujudkan suasana belajar dan proses pembelajaran agar peserta didik secara aktif mengembangkan potensi dirinya untuk memiliki kekuatan spiritual keagamaan, pengendalian diri, kepribadian, kecerdasan, akhlak mulia serta keterampilan yang diperlukan dirinya, masyarakat, bangsa dan negara. Dalam pelaksanaan fungsi dan tugasnya, guru sebagai profesi menyandang persyaratan tertentu sebagaimana tertuang di dalam Undang-undang Republik Indonesia Nomor 20 Tahun 2003 tentang Sistem Pendidikan Nasional. Dalam pasal 39 (1) dan (2) dinyatakan bahwa: Tenaga kependidikan bertugas melaksankan administrasi, pengelolahan, pengembangan, pengawasan, dan pelayanan teknis untuk menunjang proses pendidikan pada satuan pendidikan.

Salah satu standar yang memegang peran penting dalam pelaksanaan pendidikan di sekolah adalah standar pendidik dan standar kependidikan yang memegang starategis dalam menigkatkan profesionalisme guru dan mutu pendidikan di sekolah. Untuk menigkatakan mutu pendidikan, maka dibutuhkan penigkatkan kualitas guru. Kompetensi guru merupakan faktor pertama yang dapat mempengaruhi keberhasilan pembelajaran. Guru yang memiliki kompetensi tinggi akan bersikap kreatif dan inovatif yang selamanya akan mencoba menerapkan berbagai penemuan baru yang dianggap lebih baik untuk pembelajaran siswa.

Dari supervisi penelitian juga sebagai kepala sekolah di SD Negeri 04 Payaraman menunjukan bahwa mayoritas guru saat ini masih menggunakan caracara belum inovatif dalam membelajaran. Pendekatan pembelajaran ini dilakukan dengan metode ceramah dan tanya jawab. Untuk meningkatkan kualitas pembelajaran dibutuhkan pembelajaran yang merangsang siswa untuk melakukan pengamatan, penyelidikan serta mengolah informasi sehingga pada akhirnya siswa dapat memehami konsep secara bermakna. Pembelajaran yang menekankan keaktifan siswa dan berpusat pada siswa merupakan salah satu upaya yang dapat dilakukan untuk memperbaiki kualitas pembelajaran siswa.

Salah satu proses pembelajaran yang sesuai dengan teori kontruktivis adalah pembelajaran cooperative learning. Untuk mempermudah pemahaman siswa maka perlu dilakukan pembinaan kepada guru dengan menerapkan model pembelajaran dengan pendekatan cooperative learning. Oleh karena itu penulis perlu melakukan penelitian dengan judul: "Peningkatan Kinerja guru menggunakan model pembelajaran koopertif melalui supervisi akademik di SD Negeri 04 Payaraman.

Tujuan Penelitian yaitu peningkatan kinerja guru dalam menerapkan model pembelajaran cooperatif learning melalui supervisi akademik di SD Negeri 04 Payaraman.

JORNAL PROGDI PPKn, FKIP UNIVET BANTARA SUKOHARJO BEKERJA SAMA DENGAN ASSOSIASI PROFESI PENDIDIKAN PANCASILA DAN KEWARGANEGARAAN (AP3KNI) JAWA TENGAH 
CIVICS EDUCATION AND SOCIAL SCIENSE JOURNAL(CESSJ)

Volume 3 Nomor 1 Edisi Bulan Juni 2021

\section{KAJIAN TEORI}

\section{A. Kinerja}

Dalam Kamus Besar Bahasa Indonesia (Depdikbud 1990:503) kinerja berarti sesuatu yang dicapai, prestasi diperhatikan atau kemampuan kerja. Dalam sebuah artikel yang diterbitkan oleh lembaga administrasi negara merumuskan kinerja merupakan terjemahan bebas dari istilah Performence yang artinya adalah prestasi kerja atau pelaksanaan kerja atau pencapaian kerja atau hasil kerja.

Menurut Henry Simamora (2001:327) kinerja adalah tingkat pencapaian standar pekerjaan. Sementara Hadari Nawawi (2005:235) menegaskan bahwa kinerja yang diistilahkan sebagai karya adalah hasil pelaksanaan suatu pekerjaan, baik fisik/material maupun non material.

\section{B. Pembelajaran Cooperatif Learning}

Model pembelajaran kooperatif yang dimaksud dalam penelitian ini adalah model pembelajaran yang memberikan kesempatan kepada siswa untuk melakukan interaksi atau bekerja sama dalam mencapai tujuan berbagi informasi, mengambil keputusan dan memecahkan masalah. Menurut Slavin (1997) pembelajaran kooperatif merupakan suatu metode pembelajaran dimana siswa bekerja dalam kelompok yang memiliki Kompetensi heterogen. Dalam pembelajaran kooperatif, siswa bekerja sama dalam kelompokkelompok kecil untuk mempelajari materi akademik dan keterampilan antar pribadi. Setiap anggota-anggota kelompok bertanggung jawab atas ketuntasan tugas-tugas kelompok untuk mempelajari materi yang menjadi tugasnya. Ciriciri pembelajaran kooperatif

Menurut Arends (1997), pembelajaran yang menggunakan model pembelajaran kooperatifmemiliki ciri-ciri sebagai berikut :

1. Siswa bekerja dalam kelompok secara kooperatif untuk menyelesaikan materi belajarnya

2. Kelompok dibentuk dari siswa yang memiliki Kompetensi tinggi, sedang, dan rendah

3. Bila memungkinkan, anggota berasal dari suku, rasa budaya, jenis kelamin yang berbeda

4. Penghargaan lebih berorientasi pada kelompok daripada individu

\section{Suvervisi Akademik}

1. Pengertian Supervisi Akademik

Supervisi akademik intinya adalah membina guru dalam meningkatkan mutu proses pembelajaran. Oleh karena itu sasaran supervisi akademik adalah guru dalam proses pembelajaran, yang terdiri dari materi pokok 
CIVICS EDUCATION AND SOCIAL SCIENSE JOURNAL(CESSJ)

Volume 3 Nomor 1 Edisi Bulan Juni 2021

dalam proses dan hasil pembelajaran serta penelitian dan RPP, pemilihan strategi/metode/teknik pembelajaran, penggunaan media dan teknologi informasi dalam pembelajaran, menilai proses dan hasil pembelajaran serta penelitian tindakan kelas. Oleh karena itu tujuan umum pembinaan kepala sekolah melalui supervisi akademik ini adalah : (1) menerapkan teknik dan metode supervisi akademik di sekolah, dan (2) mengembangkan Kompetensi dalam menilai dan membina guru untuk mempertinggi kualitas proses pembelajaran yang dilaksanakannya agar berdampak terhadap kualitas hasil brlajar siswa.

2. Sifat-sifat supervisi akademik

Untuk mencapai tujuan yang telah ditetapkan dalam pembinaan supervisi akademik maka sifat sebagai seorang Kepala Sekolah dalam melaksanakan supervisi akademik harus memiliki kualitas sebagai berikut : (1) mendengarkan dengan sabar, (2) menunjukkan keterampilan dengan jelas, (3) menawarkan insentif atau dorongan dengan tepat, (4) mempertimbangkan reaksi dan pemahaman dengan tepat, (5) menjelaskan, merangsang, (stimulating) dan memuji secara simpatik dan penuh perhatian, (6) meningkatkan pengetahuan sendiri secara berkelanjutan.

3. Tujuan Supervisi Akademik

Sipervisi instruksional bertujuan untuk meningkatkan pertumbuhan, pengembangan, interaksi, penyelesaian masalah yang bebas kesalahan, dan sebuah komitmen untuk membangun kapasitas guru. Cogan (1973) dan Goldhammer (1969), penyusun kerangka supervisi klinis, meramalkan praktek yang akan memposisikan guru sebagai pembelajar aktif. Lebih lanjut Cogan menegaskan bahwa guru memiliki Kompetensi menjadi penanggungjawab profesional dan lebih dari pada itu ia mampu menjadi “ penganalisis kinerjanya sendiri, terbuka untuk membantu orang lain, dan mengarahkan diri sendiri”.

\section{METODE}

Lokasi Penelitian adalah di SDN 04 Payaraman beralamat di Desa Tanjung Lalang Kec. Payaraman Kabupaten Ogan Ilir Provinsi Sumatera Selatan. Pengumpulan data dilakukan dengan menggunakan observasi dan tes. Teknik analisa data menggunakan rumus teknik proporsi dengan rumus : $\mathrm{D}=[\mathrm{A} / \mathrm{N}] \mathrm{x}$ $100 \%$ (Keterangan: D: prosentase siswa yang tuntas, A: Jumlah siswa yang tuntas, $\mathrm{N}$ : Jumlah seluruh siswa (Sudjana, 2010). Hasil analisis data disajikan dalam bentuk data, table dan grafik untuk memudahkan dalam membaca data dan memprediksi kesimpulan apa yang diambil dari penelitian yang dilakukan. 
CIVICS EDUCATION AND SOCIAL SCIENSE JOURNAL(CESSJ)

Volume 3 Nomor 1 Edisi Bulan Juni 2021

\section{HASIL PENELITIAN DAN PEMBAHASAN}

\section{A. Hasil Penelitian}

Berdasarkan hasil refleksi awal sebelum tindakan dilakukan, diketahui bahwa kompetensi profesional guru dalam pengajaran, administrasi pembelajaran yang dilakukan oleh guru kelas maupun guru bidang, belum maksimal atau kurang baik. Setelah tindakan dilakukan melalui siklus ke 1 dan siklus ke 2 diketahui bahwa kompetensi profesional guru bidang, terdapat peningkatan.

Berdasarkan hasil refleksi awal sebelum tindakan dilakukan, diketahui bahwa kompetensi profesional guru dalam pengajaran, administrasi pembelajaran yang dilakukan oleh guru kelas maupun guru bidang, belum maksimal atau kurang baik. Setelah tindakan dilakukan melalui siklus ke 1 dan siklus ke 2 diketahui bahwa kompetensi profesional guru bidang, terdapat peningkatan. Hal ini sebagaimana terlihat pada tabel di bawah ini:

Tabel 1. Perolehan Skor Supervisi Admnistrasi Pembelajaran

\begin{tabular}{|c|c|c|c|c|c|}
\hline \multirow{3}{*}{$\begin{array}{l}\text { Nama dan NIP } \\
\text { OBSERVER }\end{array}$} & \multicolumn{5}{|c|}{$\begin{array}{c}\text { PEROLEHAN NILAI } \\
\text { REFLEKSI MASING MASING SIKLUS }\end{array}$} \\
\hline & \multicolumn{2}{|c|}{ SIKLUS 1} & \multicolumn{2}{|c|}{ SIKLUS II } & \multirow{2}{*}{$\begin{array}{c}\text { TOTAL } \\
\text { NILAI } \\
\%\end{array}$} \\
\hline & 1 & $\%$ & 2 & $\%$ & \\
\hline 1 & \multicolumn{2}{|c|}{2} & \multicolumn{2}{|c|}{3} & \\
\hline Raden Ali, S.Pd & 3,14 & 79 & 3,92 & 98 & 8,15 \\
\hline Erwan Kurniawan, S.Pd & 3,00 & 76 & 3,85 & 96 & 8,05 \\
\hline Raden Ali, S.Pd & 2,92 & 73 & 3,78 & 94 & 8,10 \\
\hline Jumlah & 8,13 & 228 & 11,55 & 288 & \\
\hline Rata-rata & 2,71 & $76 \%$ & 3,92 & $96 \%$ & \\
\hline
\end{tabular}

Konversi nilai :

\begin{tabular}{|l|l|l|}
\hline Siklus 1 & $76, \%$ & Cukup \\
\hline Siklus 2 & $96 \%$ & Amat Baik \\
\hline
\end{tabular}


CIVICS EDUCATION AND SOCIAL SCIENSE JOURNAL(CESSJ)

Volume 3 Nomor 1 Edisi Bulan Juni 2021

Tabel 2. Perbandingan Perolehan Skor Supervisi Pengamatan pelaksanaan Pembelajaran

\begin{tabular}{|c|c|c|c|c|c|c|}
\hline \multirow{3}{*}{$\begin{array}{l}\text { Nama dan NIP } \\
\text { OBSERVER }\end{array}$} & \multicolumn{6}{|c|}{$\begin{array}{c}\text { PEROLEHAN NILAI } \\
\text { REFLEKSI MASING MASING SIKLUS }\end{array}$} \\
\hline & \multicolumn{2}{|c|}{ SIKLUS 1} & \multicolumn{2}{|c|}{ SIKLUS II } & \multicolumn{2}{|c|}{ TOTAL NILAI } \\
\hline & 1 & $\%$ & 2 & $\%$ & & \\
\hline 1 & \multicolumn{2}{|c|}{2} & \multicolumn{2}{|c|}{3} & & \\
\hline Raden Ali, S.Pd & 3,08 & 77 & 4,00 & 100 & 3,54 & $89 \%$ \\
\hline Erwan Kurniawan, S.Pd & 3,00 & 75 & 3,91 & 97 & 3,45 & $86 \%$ \\
\hline Memi Maharani, S.Pd & 2,83 & 70 & 3,83 & 95 & 3,33 & $83 \%$ \\
\hline Jumlah & 8,83 & 222 & 11,76 & 292 & & \\
\hline Rata -rata & 2,94 & $74 \%$ & 3,92 & $97 \%$ & & \\
\hline
\end{tabular}

Konversi nilai:

\begin{tabular}{|l|l|l|}
\hline Siklus 1 & $74, \%$ & Cukup \\
\hline Siklus 2 & $97 \%$ & Amat Baik \\
\hline
\end{tabular}

\section{B. Pembahasan Hasil Penelitian}

Penelitian tindakan dilaksanakan dalam 2 siklus, yang diobservasi langsung oleh penelitian. Adapun pembahasan tiap siklus sebagai berikut ini:

\section{Siklus Satu}

Siklus I dilaksanakan selama dua hari yaitu hari pertama dilaksanakan pada hari senin tanggal 3 februari 2020 mensuvervisi berupa pernagkat pembelajaran atau persiapan untuk melaksanakan proses pembelajaran. Suvervisi ini bertujuan supaya dapat mengetahui dan mengatasi masalah tentang rendahnya kinerja guru yang ada di SDN 04 Payaraman Kecamatan Payaraman Kabupaten Ogan Ilir tahun pelajaran 2019/2020 semester II. Dalam pelaksanaan suvervisi kepala sekolah pada siklus I dilakukan dengan menggunakan teknik supervisi perorangan seperti 1) Kunjungan kelas, 2) percakapan pribadi, dan 3) Penilaian sendiri. Sedangkan teknik suvervisi kelompok meliputi 1) demonstrasi pembelajaran, 2) tugas belajar.

Supervisi hari kedua yaitu hari senin tanggal 10 Pebruari 2020 kepala sekolah berkunujng ke kelas-kelas, terutama kelas-kelas yang di jadikan sampel yaitu kelas 1A .1 B, dan kelas IV suvervisi ini melihat seberapa besar kinerja guru dalam proses pembelajaran. Suvervisi ini juga dilakukan dengan cara 
CIVICS EDUCATION AND SOCIAL SCIENSE JOURNAL(CESSJ)

Volume 3 Nomor 1 Edisi Bulan Juni 2021

diskusi dan arahan kepada guru terkait permasalahan yang dijumpai pada saat proses belajar mengajar.

Pelaksanaan supervisi kepala sekolah yang telah dilakukan pada siklus I dapat menunjukkan kinerja guru yang ada di SDN 04 Payaraman. Adapun kinerja guru tersebut secara rinci dapat dilihat pada tabel berikut ini :

Tabel 3. Perbandingan Penilaian Administrasi Perangkat Pembeljaran guru pada siklus I

\begin{tabular}{|c|l|c|c|c|}
\hline No & Kategori penilaian & Jumlah & $\%$ & Rata-rata \\
\hline 1 & Baik & 2 & $78 \%$ & \\
2 & Cukup & 1 & 73 & 0 \\
3 & Kurang Baik & 0 & 0 & 0 \\
& & & & \\
\hline \multicolumn{2}{|c|}{ Jumlah } & 12 & 100 & \\
\hline
\end{tabular}

Sumber : data primer yang diolah

Berdasarkan penilaian Administrasi pembelajaran pada siklus I dapat diketauhi bahwa guru yang memiliki kinerja baik ada 2 orang atau mencapai 78 $\%$ dari total guru yang diamati.sedangkan guru yg mempunyai kinerja yang cukup ada 1 orang guru atau $73 \%$ dari total guru yang di amati, selain itu dapat di ketauhi bahwa rata-rata penilaian kinerja guru pada siklus I adalah 2,71 atau $76 \%$ atau dengan kriteria cukup.

Sedangkan dalam pelasksanaan pembelajaran diperoleh penilaian sebagai berikut :

Tabel 4. Perbandingan Penilaian Pelaksanaan Pembelajaran Pada Siklus I

\begin{tabular}{|c|l|c|c|c|}
\hline No & Kategori penilaian & Jumlah & $\%$ & Rata-rata \\
\hline 1 & Baik & 2 & $76 \%$ & 3,04 \\
2 & Cukup & 1 & $70 \%$ & 2,83 \\
3 & Kurang Baik & 0 & 0 & 0 \\
& & & & \\
\hline \multicolumn{2}{|c|}{ Jumlah } & 3 & 100 & \\
\hline
\end{tabular}

Sumber: data primer yang diolah

Berdasarkan penilaian pelaksanaan pembelajaran pada siklus I dapat diketauhi bahwa guru yang memiliki kinerj baik ada 2 orang atau mencapai 76 $\%$ dari total guru yang diamati. Sedangkan, guru yg mempunyai kinerja yang cukup ada 1 orang guru atau $70 \%$ dari total guru yang di amati, selain itu dapat

JORNAL PROGDI PPKn, FKIP UNIVET BANTARA SUKOHARJO BEKERJA SAMA DENGAN ASSOSIASI PROFESI PENDIDIKAN PANCASILA DAN KEWARGANEGARAAN (AP3KNI) JAWA TENGAH 
CIVICS EDUCATION AND SOCIAL SCIENSE JOURNAL(CESSJ)

Volume 3 Nomor 1 Edisi Bulan Juni 2021

di ketauhi bahwa rata-rata penilaian kinerja guru pada siklus I adalah 2,94 atau $74 \%$ atau dengan kriteria cukup.

Dari hasil pelaksanaan supervisi kepala sekolah pada siklus I masih banyak terdapat kekurangan yang masih perlu di perbaiki agar mampu menghasilkan supervisi yang lebih efektif, dan diperlukan koordinasi antara guru dan kepala sekolah guna meningkatkan efektifitas pelaksanaan supervisi ini.

Sebagai bentuk refleksi dalam penelitian ini dibutuhkan perencanaan yang lebih matang lagi guna meningkatkan efektifitas pelaksanaan supervisi ini. Untuk itu dalam pelaksanaan supervisis ini perlu dilakukan perbaikan pada siklus II.

\section{Siklus Dua}

Siklus II dilaksanakan pada hari selasa tanggal 2 Maret 2020 yaitu merevisi perangkat pembelajaran guru dan hari kedua yaitu hari senin tanggal 9 Maret 2020 kepala sekolah berkunjung ke kelas-kelas yang telah di jadikan sampel yaitu kelas 1A, kelas 1B dan kelas IV. Supervisi ini sebagai bentuk refleksi dari pelaksanaan supervisi kepala sekolah yang telah dilakukan pada siklus I. Adapun peningkatan kinerja guru dalam siklus II secara rinci dapat dilihat pada tabel dibawah ini:

Tabel 5. Perbandingan Penilaian Adminitrasi Perangkat Pembelajaran Guru pada Siklus II

\begin{tabular}{|c|l|c|c|c|}
\hline No & Kategori Penilaian & Jumlah & $\%$ & Rata-rata \\
\hline 1 & Amat baik & 1 & $98 \%$ & 3,92 \\
\hline 2 & Baik & 2 & $95 \%$ & 3,81 \\
\hline 3 & Cukup & 0 & - & - \\
\hline 4 & Kurang & 0 & - & - \\
\hline
\end{tabular}

Sumber : Data Primer yang diolah

Pada siklus II dapat diketauhi bahwa guru telah mempunyai penilaian yang amat baik dan telah menunjukkan kinerja yang baik pada penilaian administrasi pembelajaran dan telah mengacu kepada hal-hal yang telah di tentukan di dalam lembaran obvsevasi seingga nilai kinerja guru dapat mencapai $96 \%$ atau 3,96.

Sementara itu penilaian dalam pelaksanaan pembelajaran dapat di lihat sebagai berikut : 
CIVICS EDUCATION AND SOCIAL SCIENSE JOURNAL(CESSJ)

Volume 3 Nomor 1 Edisi Bulan Juni 2021

Tabel 6. Perbandingan Penilaian Pelaksanaan Perangkat Pembelajaran Guru pada Siklus II

\begin{tabular}{|c|l|c|c|c|}
\hline No & \multicolumn{1}{|c|}{ kategori prnilaian } & Jumlah & $\%$ & Rata-rata \\
\hline 1 & Amat baik & 1 & $100 \%$ & 4,00 \\
\hline 2 & Baik & 2 & $95 \%$ & 3,87 \\
\hline 3 & Cukup & 0 & 96 & - \\
\hline 4 & Kurang & 0 & - & - \\
\hline
\end{tabular}

Sumber : Data Primer yang diolah

Pada siklus II dapat diketauhi bahwa guru telah mempunyai penilaian yang amat baik dan telah menunjukkan kinerja yang baik pula serta selama proses pembelajaran telah mengaju kepada hal-hal yang telah di tentukan di dalam lembaran ovsevasi seingga nilai kinerja guru dapat mencapai $97 \%$ atau 3,92 atau dengan kategori Amat Baik.

Dengan demikian dapat diketauhi bahwa kinerja guru yang ada di SDN 04 Payaraman mengalami peningkatan setelah dilaksanakannya supervisi pada siklus II ini. Peningkatan Penilaian kinerja guru dapat dilihat dari hasil penilaian administrasi yang semula mempunyai nilai rata-rata 2,71 meningkat menjadi 3,92 , atau semula $76 \%$ meningkat menjadi $96 \%$ sedangkan penilaian dalam pelaksanaan pembelajaran dapat dilihat sebagai berikut yang semula nilainya 2,94 meningkat menjadi 3,92 atau 74\% meningkat menjadi $97 \%$ atau dengan kategori Amat Baik oleh karena itu penelitian pada siklus II ini berhasil.

\section{Pembahasan}

Berdasarkan hasil penelitian tindakan sekolah yang terkait dengan upaya meningkatkan kinerja guru melalui pelaksanaan supervisi kepala sekolah yang ada di SDN 04 Payaraman, maka dapat ditarik pembahasan bahwa pelaksanaan supervisi kepala sekolah yang ada di SDN 04 Payaraman Kecamatan 04 Payaraman Kabupaten Ogan Ilir selama ini belum dapat dilaksanakan secara efektif. Namun setelah pelaksanaan tindakan ini membuktikan bahwa pelaksanaan supervisi kepala sekolah mampu memberikan kontribusi yang positif terhadap peningkatan motivasi dan kinerja guru yang ada di SDN 04 Payaraman Kecamatan Payaraman Kabupaten Ogan Ilir Tahun Pelajaran 2019/2020.

Dari hasil penelitian ini terbukti bahwa pelaksanaan supervisi kepala sekolah yang dilakukan secara efektif akan dapat meningkatkan kinerja guru yang ada di SDN 04 Payaraman Kecamatan Rambang Kuang, Kabupaten Ogan Ilir Tahun 2019/2020. Hal ini terbukti dari adanya peningkatan penilaian motivasi dan kinerja guru pada saat pra siklus, siklus I dan siklus II.

Adapun peningkatan motivasi kerja guru yang ada di SDN 04 Payaraman Kecamatan Payaraman Kabupaten Ogan Ilir tahun 2019/2020 
CIVICS EDUCATION AND SOCIAL SCIENSE JOURNAL(CESSJ)

Volume 3 Nomor 1 Edisi Bulan Juni 2021

dengan adanya supervisi kepala sekolah secara rinci dapat dilihat pada grafik di bawah ini:

Hasil observasi pada siklus II, menunjukan terjadinya perubahan, karena yang tadinya administrasi pembelajaran yang tidak ada, secara keseluruhan menunjukan skor rata-rata 3,92 =96\% dengan katogori Amat baik. Sedangkan pelaksanaan pembelajaran juga mengalami peningkatan dengan ratarata semula 2,94 atau $74 \%$ meningkat menjadi 3,92 atau 97\% dengan kategori Amat Baik Tenggang waktu antara siklus I dan siklus II kurang lebih 1 bulan.

\section{SIMPULAN}

\section{Kesimpulan}

Profesionalisasi adalah proses usaha, menuju ke arah terpenuhinya persyaratan suatu jenis model pekerjaan ideal yang berkemampuan, sedangkan supervisi akademik bidang administraasi pembelajaran merupakan supervisi yang menitik beratkan pengamatan supervisor ada aspek-aspek administratif yang berfungsi sebagai pendukung dan pelancar terlaksanya pembelajaran. Kegiatan penelitian ini menghasilkan beberapa kesimpulan, yaitu:

1. Profesionalisasi di Sekolah Dasar Negeri 04 Payaraman melalui kegiatan supervisi akademik bidang administrasi pembelajaran dengan tiga siklus.

2. Siklus I, mnunjukan skor rata-rata $68,4 \%$ dengan katagori baik, siklus II menunjukan skor rata-rata 94,00\% dengan katagori sangat baik dan Supervisi yang dilaksankan oleh supervisor, dapat meningkatkan profesionalisme guru, sehingga dapat meningkatkan mutu pendidikan.

\section{Saran-saran}

1. Bagi para Pengawas Sekolah, diharapkan kegiatan supervisi di sekolah binaannya, dilaksankan secara berkala.

2. Bagi para tenaga pendidik, hendaknya menjadi tenaga yang profesional demi peningkatan mutu pendidika.

3. Guru yang menunjukan sebagai obyek penelitian, diharapkan

4. dapat menularkan kepada rekan-rekan guru lainnya, sehingga imbasnya dapat meningkatkan profesionalisme guru khususnya di Sekolah Dasar Negeri 04 Payaram 
CIVICS EDUCATION AND SOCIAL SCIENSE JOURNAL(CESSJ)

Volume 3 Nomor 1 Edisi Bulan Juni 2021

\section{REFERENSI}

Arends. (1997). Model-Model Pembelajaran Inovatif berorientasi Konstuktivitis. Jakarta: Prestasi Pustaka Publisher.

Hadadari, Nawawi. (2005). Manajemen Sumber Daya Manusia. Yogyakarta: Gadjah Mada University Press.

Hamalik, Oemar. (2007). Fsikologi Belajar Mengajar. Jakarta: PT Bumi.

E. Mulyasa. (2003). Menjadi Guru Profesional. Jakarta: PT.Remaja Rosdakarya.

Simamora Henry. (2001). Manajemen Sumber Daya Manusia: Jokyakarta.

Slavin, E Robert. (1997). Cooperative Learning. Second Edition. Allyn \& Bacon. A Simon \& Aschuster Company.

Slavin, E Robert. (2004). Cooperative Learning Teori, Riset dan Praktik. Bandung: Nusa Media Bahasa 